\title{
PROAKTIVNO UPRAVLJANJE RIZICIMA: KONTROLING
}

\author{
Aleksandra Todorović-Dudić ${ }^{1}$ \\ Veselin Petrović, \\ Ranko Bojanić2
}

\author{
1 Univerzitet Privredna akademija \\ Novi Sad, \\ Fakultet za ekonomiju i inženjerski \\ menadžment, \\ Novi Sad, Srbija \\ ¿Univerzitet u Novom Sadu, \\ Fakultet tehničkih nauka, \\ Novi Sad, Srbija
}

\begin{abstract}
Apstrakt:
U uslovima povećane neizvesnosti u međunarodnom poslovanju kontroling ima bitnu ulogu, kako na strateškom, tako i na operativnom nivou. Cilj efikasnog sistema upravljanja rizicima je da osigura opstanak kompanije, analizira korporativni rizik i proceni potencijalni efekat ovog rizika na kompaniju. Uobičajeno je da se rizici prikazuju u obliku dodatnih troškova primenom raznih instrumenata koje koristi kontroling. Kontroling je moćan alat za upravljanje koji povezuje strateško planiranje, sistem Balanced Scorecard i budžetiranje. Moderni kontroling je danas proaktivni, strateški i poslovno orijentisani pristup koji pomaže u rešavanju izazova sa kojima se kompanije suočavaju.
\end{abstract}

Ključne reči:

kontroling funkcija, upravljanje rizicima, strateško planiranje, Balanced Scorecard, budžetiranje.

\section{UVOD}

Da bi držale korak sa promenjivim i sve složenijim poslovnim okruženjem, kompanije moraju da se prilagode i menjaju svoje alate za strateško upravljanje. Na operativnom nivou, raširena upotreba savremenih informacionih i komunikacionih tehnologija, omogućila je radikalni redizajn poslovnih procesa i pomogla da se efikasno iskoriste kontroling procesi (Erben, 2002).

Globalizacija ekonomije, sve veća internacionalizacija tržišta, značajno utiče na uslove poslovanja na domaćem i inostranom tržištu. Razvoj informacione i telekomunikacione tehnologije takođe pomaže da se promoviše razvoj i širenje poslovanja i van domaćeg tržišta. Svaka kompanija kako bi uspešno obavila svoj posao mora pronaći i zadržati svoju konkurentsku prednost. U tu svrhu, preduzeća moraju efektivno i efikasno koristiti ogromne količine informacija. Pod uslovima povećane neizvesnosti u međunarodnom poslovanju kontroling ima bitnu ulogu, kako na strateškom, tako i na operativnom nivou. Kontroling je u prošlosti imao uglavnom ulogu prilikom analiziranja, planiranja i na području kontrole. Trenutno, kontroling se fokusira, pre svega, na stvaranje i upravljanje takvim sistemima koji su od ključnog značaja za poslovni uspeh kompanije na tržištu. Kompanije sve više upravljaju poslovanjem i putem ne-novčanih pokazatelja (zadovoljstvo kupaca, produktivnost i sl.), dok se finansijski pokazatelji više koriste u dugoročnom upravljanju. Sve veći značaj kontrolinga u međunarodnom poslovanju pokazuje otvorenost kompanija kao ekonomskog sistema, kao i povećanje konkurentskog pritiska. Efikasan kontroling je nezamenjiv, posebno u situaciji povećanja neizvesnosti u savremenim uslovima poslovanja (Jamborova, 2012).

\section{ULOGA KONTROLINGA}

Korespondencija:

Aleksandra Todorović-Dudić

e-mail:

aleksandra.todorovic-dudic@hemofarm.com
Poslednjih godina raširena upotreba moderne informacione i komunikacione tehnologije uzrokuje fundamentalne promene u poslovnom okruženju za mnoge kompanije, koje su napravile radikalne izmene u svojim lancima vrednosti. Ne iznenađuju pro- 
mene u poslovnom okruženju koje imaju značajne posledice na kontroling. Pre svega, kontroleri su postali mnogo važniji. Danas, čak i „startup“ kompanije počinju da preispituju značaj efektivnog i efikasnog kontrolinga.

Alarmantan je podatak nedavne američke studije (Hagen, 2004) u kojoj se navodi da je vodeći razlog za propast poslovanja u $82 \%$ kompanija - loš menadžment. Lošem menadžmentu nije pomogla ekonomska kriza koja već godinama negativno utiče na poslovanje kompanija širom sveta. Međutim, upravo u kriznim vremenima važno je praviti što manje menadžerskih grešaka. U Srbiji, kao i u okolnim zemljama bivše Jugoslavije, kontroling, odnosno procene rizika menadžerskih odluka, se primenjuju u nekim preduzećima. U Srbiji, kontroleri imaju široku ulogu koja uključuje i strateško i operativno delovanje kao oblik podrške menadžmentu prilikom donošenja odluka, dok je, kada je reč o kompanijama koje su u stranom vlasništvu, kontroling uglavnom sveden na operativni nivo, odnosno na poslovno izveštavanje, dok se strateški kontroling primenjuje u matičnim zemljama. Naime, činjenica je da je za uspešni kontroling potrebna promena kulture upravljanja, tj. više odgovornosti i etičnosti u vođenju preduzeća.

Kompanije koje još uvek nisu shvatila ulogu kontrolinga i implementirala ga, ubrzo mogu biti iznenađena razvojem i rastom kompanija koje imaju mnogo godina uspešno razvijen kontroling.

Da bi vršilac kontrolinga bio uspešan u svom poslu potrebna su mu multidisciplinarna znanja, kako bi na temelju mnogobrojnih podataka iz preduzeća, ali i izvan njega, prikupio one koji su nužni menadžerima i svima koji upravljaju preduzećem za kvalitetno odlučivanje.

Kontroling je umeće (know-how), filozofija upravljanja na osnovi ekonomske logike racionalnosti, funkcija preduzeća koja ima zadatak da koordinira poslovne procese i njihove pojedine delove, te pomoću izgradnje integrisanog i objedinjenog sistema upravljanja, koji svoje temelje nalazi na jasno definisanoj viziji, misiji i ciljevima, bude stručna pomoć menadžmentu. U praksi je kontroling značajna ekonomska disciplina (Bojanić, 2012).

\section{UPRAVLJANJE RIZICIMA}

U suštini, cilj efikasnog sistema upravljanja rizicima je da osigura opstanak kompanije, odnosno da zacrtani ciljevi budu postignuti. U tom kontekstu, potrebno je koliko je to moguće, da se potpuno identifikuju i analiziraju korporativni rizici i da se proceni efekat ovih rizika na kompaniju. Finansijska i ekonomska kriza su ukazali na značaj upravljanja rizicima i doveli do povećanja svesti o tome.

Upravljanje rizicima u poslovanju obuhvata identifikovanje, evidentiranje, analiziranje, ocenjivanje i proveravanje rizika, kao i izvođenje i implementiranje odgovarajućih mera za sprečavanje rizika. Uobičajeno je da se rizici prikazuju u obliku dodatnih troškova kod raznih instrumenata koje koristi kontroling. Za upravljanje rizicima i šansama, za kontroling je bitno da se oni što potpunije identifikuju, klasifikuju i kvantifikuju. Procenjeni pojedinačni rizici se zatim sabiraju u ukupnu poziciju rizika cele kompanije, uzimajući u obzir sve međuzavisnosti.

Rizik u poslovanju se ne može izbeći, jer je on faktor poslovanja, ali se njime mora upravljati.

\section{GLOBALNA PERSPEKTIVA}

Ako lideri preduzeća 21. veka žele da budu različiti od konkurenata i vode svoje kompanije ka rastu, moraju imati sposobnost da vode svoje kompanije ka veoma rizičnim i opasnim tržišnim prilikama.

Mnoštvo je rizika sa kojima se suočavaju kompanije danas, a neke od njih mogu i da ugroze uspeh organizacije i na kraju dovedu do smanjenja njene vrednosti. Sile poput globalizacije i geopolitičkog okruženja u kojem organizacije rade dodatna su kompleksnost poslovanja, i povećavaju već postojeći rizik. Tehnologija i internet zahtevaju od kompanija da preispitaju svoje poslovne modele, osnovne strategije i ciljna tržišta. Kupci imaju sve veće zahteve za prilagođavanje proizvoda i usluga, što dovodi do još više rizika. Ako se ne ispune očekivanja kupaca, to može da utiče na udeo na tržištu i, na kraju, na prihod i profit. Spajanja i restrukturiranja kompanija izazivaju promene u odgovornosti menadžmenta, koji takođe stvara potencijal za rizike preduzeća. Imajući u vidu sve ove stvari, lideri u kompanijama moraju da imaju povećano stanje svesti o potrebi za holističkim načinom upravljanja rizikom i jačom upravljačkom strukturom u njihovoj organizaciji. Uspešne kompanije su uvek imale fokus na upravljanju rizikom. Opšta pretpostavka je da izvršni menadžment ima fokus na strateški rizik sa kojim se suočava preduzeće u kratkom roku i tokom trajanja strateškog plana. Kako organizacije postaju sve složenije i u službi globalnog tržišta, rukovođenje kompanijom je izazov koji se mora u potpunosti razumeti. Rukovodstvo koje je orijentisano prema rizicima ne znači da će u kompaniji izazvati averziju prema riziku, već će nastojati da identifikuje, proceni i upravlja rizicima. Suština je sagledati rizik širom preduzeća i adekvatno upravljati rizikom za dobrobit vlasnika kapitala.

\section{INTEGRACIJA KONTROLINGA U UPRAVLJANJU RIZICIMA}

Kontroling predstavlja jednu od najznačajnijih funkcija čiji je zadatak da rešava konkretne probleme prilagođavanja unutrašnjim i spoljašnjim promenama koje nadolaze. Kontroler daje značajan doprinos i podršku upravljanja preduzećem kao strateški partner rukovodstvu preduzeća. Kontroling je moćan alat za upravljanje. 
Odnos između strateškog planiranja, BSC-a (Balanced Scorecard) i budžetiranja prikazan je na Slici 1.

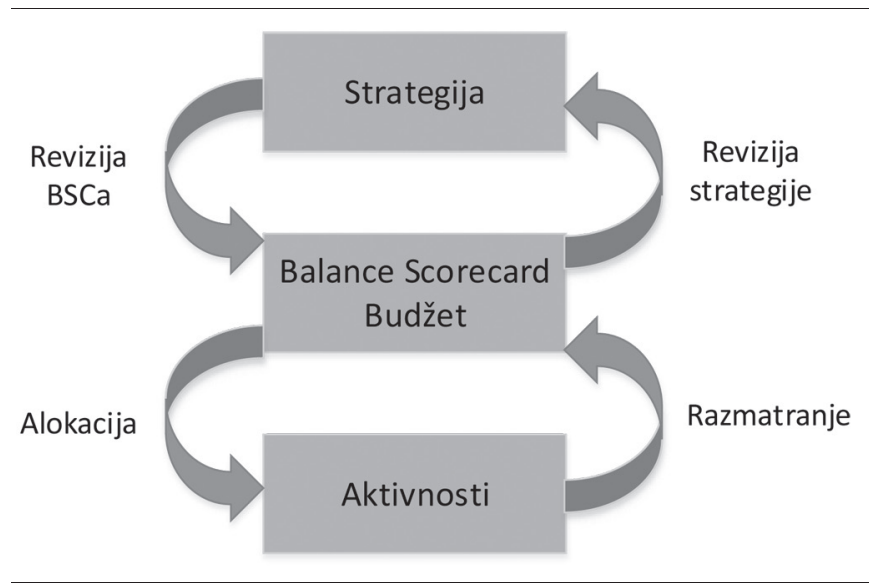

Slika 1. Strategija, BSC i Budžet

Izvor: The Association of Accountants and Financial Professionals in Business (2011)

\section{Strateško planiranje}

Prilikom formulisanja strategije kompanije, rukovodstvo analizira svoje strateške alternative i identifikuje događaje koji bi mogli ugroziti njihovo ostvarenje. Kako su rizici ugrađeni u svaku stratešku alternativu, identifikovani se postavljaju na mapu rizika. Neke strategije mogu imati rizik koji je izvan kontrole kompanije, tada se donosi odluka da li se prihvataju takvi rizici. Druge strategije mogu biti veoma rizične, ali se njima može upravljati i iste se mogu pažljivo pratiti, na bazi čega će se donositi odluke o prihvatanju rizika. Druge strategije mogu biti rizične, ali će se doneti odluka da se nastavi kroz ,joint venture“ odluke o prihvatanju rizika.

\section{Balanced Scorecard}

Jedan od osnovnih instrumenata kontrolinga je Balanced Scorecard. BSC je alat za komuniciranje i primenu strategije kroz celu kompaniju. BSC prevodi strategiju kompanije u četiri ključne perspektive (Kaplan \& Norton, 1996):

- Perspektiva potrošača - performanse preduzeća na tržištu i u odnosu prema potrošačima,

- Perspektiva internih procesa - performanse preduzeća u efikasnosti vođenja internih poslovnih procesa,

- Perspektiva inovacije i učenja - performanse preduzeća u inoviranju i sticanju novih znanja i

- Finansijska perspektiva - finansijske performanse preduzeća

BSC je skup mera, organizovan u tzv. perspektive. Mere se odnose na četiri glavne upravljačke perspektive, i imaju sve obuhvatan pogled na poslovanje. U principu, BSC spaja poslovne strategije u sveobuhvatni sistem upravljanja. BSC objedinjuje finansijske i operativne mere i fokusira se kao na kratkoročne tako i na dugoročne ciljeve.

Da bi strategija bila razumljiva svima i da bi je svi sprovodili i imali jedinstvene ciljeve, potrebno je izvući ono najbitnije iz strategije, predstaviti je jasno da je razumeju svi zaposleni. Spuštanje strategije na sve grupe na svim nivoima organizacije, omogućava da iste deluju u skladu sa tim znanjem, pretvarajući ga u vrednost za celo društvo.

Ako je jasno ono što nedostaje u većini planova, strateška mapa deluje kao snažna pokretačka snaga, jer pretvara nejasne strateške planove u jasne i jednostavne ciljeve koji, ako ih pravilno postavimo, govore šta moramo preduzeti. Strateška mapa deluje kao rani signal uzbune za strategiju kompanije, signalizirajući nevolje kada neki od pokazatelja sugeriše na problem. KPI za svaku perspektivu služi i kao ključni pokazatelj rizika, iako nisu prvobitno izabrani za tu svrhu. Na primer, ako se ne postigne cilj zadovoljstvo kupaca, to sugeriše da postoje neki rizici koji se odnose na tu stavku. Isti metod se može koristiti i za praćenje strategije i rizika.

Kao što je prikazano na slici 2, BSC počinje sa posebnim ciljevima za određenu perspektivu. Dalje, za svaki od tih ciljeva, ključni rizici su identifikovani zajedno sa predloženim procesom kontrole. Fokus je na identifikovanju rizika kao

\begin{tabular}{|c|c|c|c|c|c|c|c|c|c|}
\hline \multicolumn{4}{|c|}{ Učenje i razvoj ciljeva } & \multirow{2}{*}{$\begin{array}{c}\text { Predlog } \\
\text { kontrole } \\
\text { proces }\end{array}$} & \multirow{2}{*}{$\begin{array}{l}\text { Zona } \\
\text { fokusa }\end{array}$} & \multicolumn{2}{|c|}{ Uticaj na proces } & \multirow{2}{*}{ Komentar } & \multirow{2}{*}{$\begin{array}{l}\text { Vlasnik korek } \\
\text { tivne akcije }\end{array}$} \\
\hline Broj & Cilj & Broj rizika & Rizik & & & $\mathrm{Na}$ mestu & Efikasnost ${ }^{*}$ & & \\
\hline & & & & & & & & & \\
\hline & & & & & & & & & \\
\hline & & & & & & & & & \\
\hline & & & & & & & & & \\
\hline & & & & & & & & & \\
\hline
\end{tabular}

* Efikasnost rejtinga: od 1 do 10 s tim da je 10 veoma efikasan

Slika 2. BSC i strateška procena rizika 
strateških, operativnih i finansijskih. Postavljaju se pitanja: „Da li je na pravom mestu? Ako jeste, koliko je efikasan?“ Poslednja kolona se fokusira na identifikaciju vlasnika rizika, koji se smatra odgovornim za upravljanje. Održavanje BSC rizika na intranetu kompanije, omogućava se da se BSC razmotri u bilo kom trenutku, i da se na taj način upravlja rizikom.

\section{Budžetiranje}

Budžetiranje je osnovni element poslovnog ciklusa, jer pomaže u prevođenju strategije firme u akciju. Budžet kompanije odražava finansijsku stanje tekuće godine da se postigne dugoročna strategija organizacije. U budžetskom procesu, rukovodstvo strateške poslovne jedinice predstavlja svoj plan profita višem menadžmentu, koji ga preispituje i postavlja pitanja kako bi otkrio potencijalni rizik u brojkama. Mapa rizika pruža informacije višem rukovodstvu o tome šta su glavne pretnje za ispunjenje finansijskog plana za tu godinu (Koester, 2011). Takođe, ona pruža polaznu tačku u procesu revizije budžeta bez potrebe da se gubi vreme u otkrivanju budžetskog rizika. Radne jedinice treba da znaju svoje rizike ako žele da imaju ikakve šanse za ostvarivanje plana. Kada se donosi odluka da se ublaži neki rizik, važno je da se razume njegov uticaj na strukturu troškova, kao i to koliki su troškovi ublažavanja ili prihvatanja rizika ugrađeni u cenu proizvoda ili usluge.

Koliko kontroling doprinosi uspehu upravljanja preduzećem pokazuje istraživački rad (Todorović-Dudić, 2015), gde je analizirana 51 kompanija različitih privrednih aktivnosti. $88,24 \%$ anketiranih preduzeća je ocenilo ocenom pet doprinos koji ima kontroling u upravljanju poslovanjem preduze-

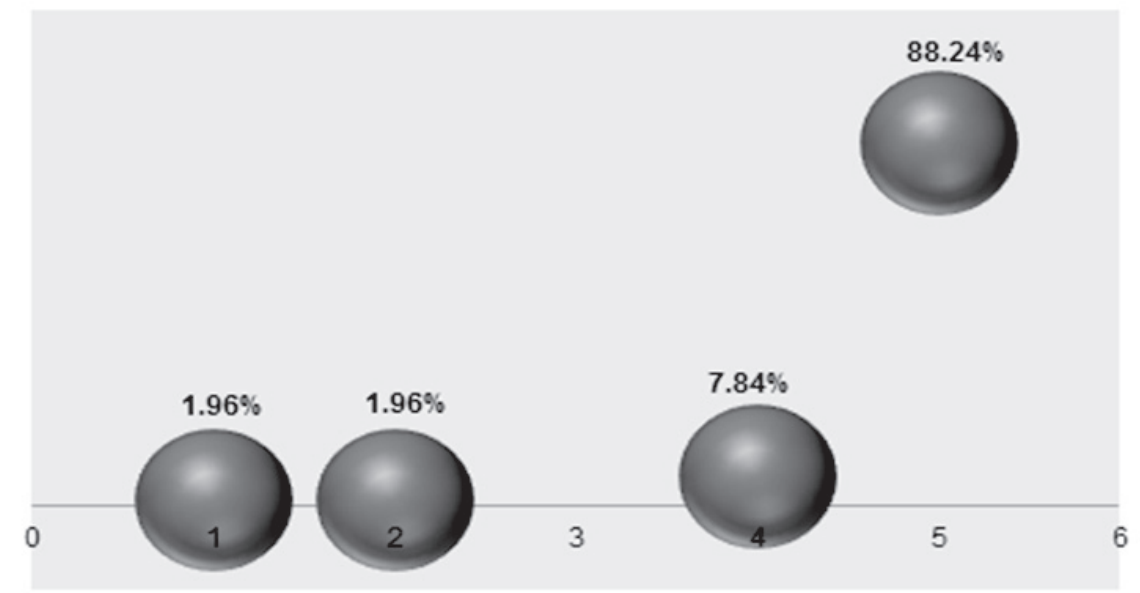

Slika 3. Doprinos kontrolinga efikasnosti i upravljanju poslovanjem

Izvor: Todorović-Dudić (2015)

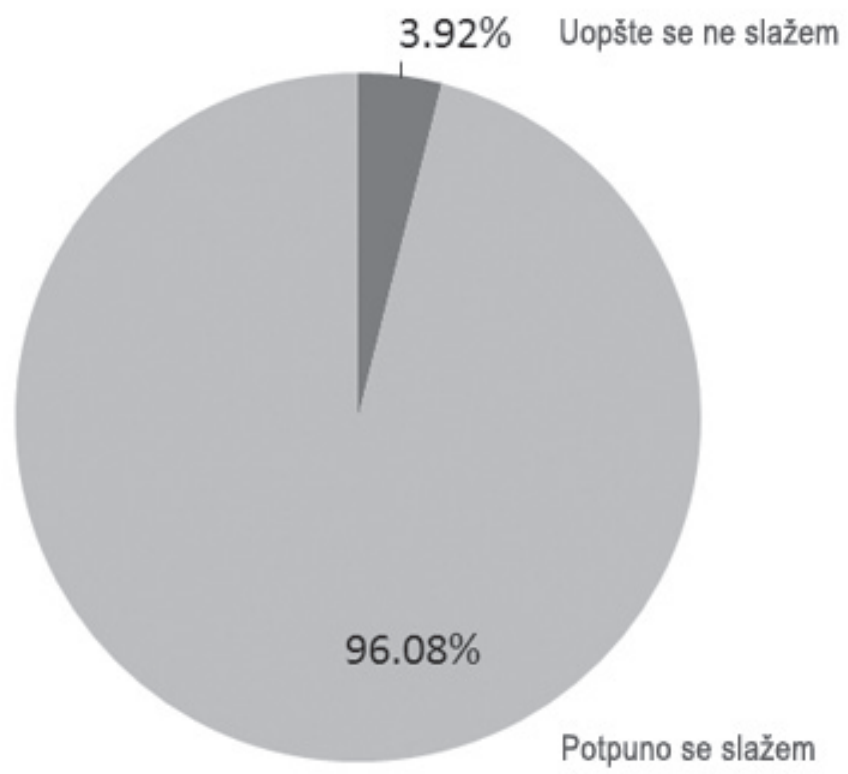

Slika 4. Uvođenjem kontrolinga povećana mogućnost identifikacije rizika poslovanja

Izvor: Todorović-Dudić (2015) 
ća (Todorović-Dudić, 2015). Takođe, 96,08\% preduzeća se u potpunosti slaže da se implementacijom kontrolinga povećava mogućnost identifikacije rizika poslovanja.

\section{ZAKLJUČAK}

Cilj upravljanja rizicima obuhvata identifikovanje, evidentiranje, analiziranje, ocenjivanje i proveravanje rizika, kao i izvođenje i implementaciju odgovarajućih mera za sprečavanje rizika. To se postiže u okviru utvrđene politike upravljanja rizicima i strateške orijentacije. Svaka upravljačka aktivnost, a samim tim i kontroling, suočava se sa činjenicom da budućnost ne može da se predvidi, i zato postoje rizici i šanse. Upravljanje rizicima omogućava eksplicitno ugrađivanje rizika i šansi u kontrolingu putem prikazivanja bitnih planskih pretpostavki, što rezultuje planiranje koje je bliže realnosti. Kontroling je prvenstveno razvijen kao odgovor na makroekonomske turbulencije tokom dvadesetih i tridesetih godina prošlog veka. Kako je globalna ekonomija jačala, kompanije su polako rasle i bile su suočene sa sve većim izazovima u oblasti komunikacije, koordinacije i upravljanja. Kontroling je razvijen kao način za regulisanje čitavog poslovanja i upravljanja (Perović, 2005). Ekonomska i globalna struktura dvadeset prvog veka, koja je oblikovana svetskom ekonomskom krizom, pravi novu sredinu punu izazova za kontroling. Jača konkurencija, velika promenljivost tržišta, kraći ciklus inovacija i jači pritisak na profitne margine primoravaju današnje kompanije da reaguju brže, i sa boljom strategijom, kako bi bili uspešne. Mnoge industrije kao što su zdravstvo, automobilska industrija, telekomunikacije i industrija potrošnih dobara se suočavaju sa drastično promenjenim okruženjem koje karakterišu obrazovaniji kupci, globalne cene i transparentnost kvaliteta, „ometanje inovacija“, skraćivanje životnog ciklusa proizvoda, jako nestabilna tržišta i povećanje globalne konkurencije. Dok reaktivan i finansijski orijentisan kontroling dodaje vrednost u stabilnom okruženju, za promenjivo okruženje najbolje bi bilo da se koristi proaktivni, strateški i poslovno orijentisani pristup.

\section{LITERATURA}

Bojanić, R. (2012). Razvoj modela za praćenje uspešnosti rada visokoškolskih obrazovnih institucija: doktorska disertacija. Novi Sad: Fakultet tehničkih nauka, Univerzitet u Novom Sadu.

Erben, R.F. (2002). E-controlling: Ten Challenges for Controlling and Management Accounting. Journal of Corporate Accounting \& Finance, 13(5), 55-62.

Jamborova, E.M. (2012). Controlling in international business and its growing importance in terms of socio-economic crisis. Preuzeto 6. maja 2016. sa http://www.cutn.sk/Library/proceedings/mch_2012/editovane_prispevky/Jamborov\%C3\%A1

Kaplan, R.S., \& Norton, D.P. (1996). The balanced scorecard: Translating strategy into action. Boston, Mass: Harvard Business School.

Koester, E. (2011). Green entrepreneur handbook: The guide to building and growing a green and clean business. Boca Raton, FL: CRC.

Perović,V. (2004). Kontroling koncept preduzeća. Privredna izgradnja: časopis ekonomista Vojvodine, 47(1-2), 113-135.

The Association of Accountants and Financial Professionals in Business. (2011). Enterprise Risk Management Frameworks, Elements and Integration. Prezeto 16. maja 2016. sa http:// www.stjohns.edu/sites/default/files/documents/academics/ tobin/enterprise_risk_management_frameworks.pdf

Todorović-Dudić, A. (2015a). Model korporativnog kontrolinga kao instument upravljanja industrijskim sistemima: doktorska disertacija. Novi Sad: Fakultet tehničkih nauka, Univerzitet u Novom Sadu.

Todorović-Dudić, A. (2015b). Controlling Between Autonomy and Heteronomy. International Journal of Industrial Engineering and Management, 6(4), 171-177.

\section{PROACTIVE RISK MANAGEMENT: CONTROLLING}

\section{Abstract:}

Controlling has an important strategic and operational role in circumstances of growing uncertainty in international business. The goal of efficient risk management is ensuring company survival, analyzing corporative risk and estimating potential effect of the risk to the company. The risks are generally presented as additional costs by using various controlling instruments. Controlling is a powerful management tool that incorporates strategic planning, Balanced Scorecard system and budgeting. Modern controlling today represents a proactive, strategic and business-oriented approach that assists companies in addressing the challenges they face.

\section{Keywords:}

controlling function, risk management, strategic planning, Balanced Scorecard, budgeting. 